\title{
Golgi Protein 73 versus Alpha-Fetoprotein as a New Biomarker in Early Diagnosis of Hepatocellular Carcinoma
}

This article was published in the following Dove Press journal: International Journal of General Medicine

\author{
Omaima Mohamed $\mathrm{Ali}^{1}$ \\ Hussein Ahmed El Amin ${ }^{2}$ \\ Yousry Lotfy Sharkawy' \\ Adnan Ahmed Mohamed $\mathrm{Ali}^{3}$ \\ Emad Farah Mohammed \\ Kholef (iD ${ }^{4}$ \\ Wael Abd Elgwad Elsewify (iD) \\ 'Internal Medicine Department, Faculty \\ of Medicine, Aswan University, Aswan, \\ Egypt; ${ }^{2}$ Internal Medicine Department, \\ Faculty of Medicine, Assuit University, \\ Assuit, Egypt; ${ }^{3}$ Tropical Medicine and \\ Gastroenterology Department, Faculty of \\ Medicine, Assuit University, Assuit, Egypt; \\ ${ }^{4}$ Clinical Pathology Department, Faculty \\ of Medicine, Aswan University, Aswan, \\ Egypt
}

Background: Screening of early hepatocellular carcinoma (HCC) diagnosis is the greatest challenge for hepatologists. Alpha-fetoprotein (AFP) is the most common non-invasive biomarker used in HCC diagnosis.

Objectives and Aims: To make a comparison between the new biomarker Golgi protein 73 (GP73) versus the standard biomarker AFP in the diagnosis of HCC.

Methods: Our study was a case-control study, and 60 patients were included in the study. They were divided into two groups: 1) HCC patients with either chronic HBV or HCV infection ( $\mathrm{n}=30$ ); and 2) non-HCC patients with HBV or HCV infection who had either chronic hepatitis or liver cirrhosis $(n=30)$. In addition, 30 healthy volunteers were included as a control group. Patients were subjected to liver function tests, kidney function tests, serum Golgi protein 73 and AFP levels. Imaging diagnosis of HCC was done by computed tomography (CT) or magnetic resonance imaging (MRI) based on American Association for the Study of Liver Diseases (AASLD) practice guidelines.

Results: Statistically significant differences between groups in terms of serum AFP $(p<0.001)$ and GP73 $(p<0.001)$ were found. Non-HCC patients (chronic hepatitis and liver cirrhosis) and HCC patients had significantly higher AFP and GP73 than the control group. In addition, patients with HCC had significantly higher AFP and GP73 than chronic hepatitis and cirrhotic patients. GP73 had higher diagnostic performance than AFP. At a cut-off value of $\geq 8.4 \mathrm{ng} / \mathrm{mL}$, GP73 yielded a sensitivity of $86.7 \%$ and specificity of $89 \%$ for the discrimination between HCC and normal populations. Similarly, at a cut-off value of $\geq 8.45$ $\mathrm{ng} / \mathrm{mL}$, GP73 yielded a sensitivity of $83.3 \%$ and specificity of $84 \%$ for the discrimination between HCC patients and non-HCC patients. On the other hand, AFP at a cut-off value of $\geq 2.4 \mathrm{ng} / \mathrm{mL}$ yielded a sensitivity of $75.4 \%$ and specificity of $90 \%$ for the discrimination between HCC and normal populations; and at a cut-off value of $\geq 20.85 \mathrm{ng} / \mathrm{mL}$, AFP yielded a sensitivity of $72.2 \%$ and specificity of $86.2 \%$ for the discrimination between HCC and nonHCC patients.

Conclusion: Golgi protein 73 is a promising and accurate biomarker for early detection of HCC.

Keywords: liver cirrhosis, HCC, AFP, Golgi protein 73

\section{Introduction}

Hepatocellular carcinoma (HCC) is considered to be the sixth most common cancer all over the world, and believed to be the second cause of cancer-induced mortality for men and sixth for women; according to GLOBOCAN, in 2018, about 745,517 deaths were a direct result of HCC. HCC arises in most cases as a complication of
Elsewify

Department of Internal Medicine, Faculty of Medicine, Aswan University, Aswan 81528 , Egypt

Tel +201001657295

Fax +20973480449

Email waelelsewify@yahoo.com 
end-stage liver disease, secondary to either viral hepatitis (chronic hepatitis $\mathrm{C}$ infection or chronic hepatitis $\mathrm{B}$ infection) or other non-viral chronic liver diseases. ${ }^{1}$

Most cases of HCC are asymptomatic in the early stages so most HCC cases are detected in later stages of the disease, leading to difficulty in treatment and a low possibility to reach curability states. Curative treatment options such as surgical resection or liver transplantation can be applied to a small number of patients with preserved liver function. The HCC prognosis remains disappointing, with a 5 -year survival rate of $6.9 \%$, an incidenceto-mortality ratio of 0.95 and a median overall survival rate of only 11 months. Therefore, early diagnosis of HCC is the cornerstone for improved patient outcomes. ${ }^{2}$

Multiple biomarkers, eg, alpha-fetoprotein (AFP), AFPL3 or Des- $\gamma$-carboxyprothrombin (DCP), are used or under investigation for screening and early detection of HCC patients. AFP is the most common and most frequently used biomarker. However, sensitivity ranges from $25 \%$ for tumors less than $3 \mathrm{~cm}$ to $50 \%$ for lesions more than $3 \mathrm{~cm}$ in diameter. Thus, there is an unmet need for developing new biomarkers for $\mathrm{HCC}$ with better diagnostic performance. ${ }^{3}$

Golgi Protein 73 (GP73) is a 73-kD resident Golgi membrane protein of unknown function. GP73 messenger RNA levels were detected in HCV-related human liver disease. Investigators also considered GP73 as a potential biomarker for early detection of HCC. Serum GP73 levels demonstrate increased sensitivity in relation to AFP in the early diagnosis of $\mathrm{HCC}{ }^{4}$

\section{Aim of Work}

There is a scarcity in the published literature regarding the diagnostic performance of GP73 compared to AFP for early detection of cirrhosis-related HCC. Therefore, we conducted this study aiming to evaluate the diagnostic accuracy of GP73 compared to AFP for early detection of cirrhosis-related HCC.

\section{Methods}

\section{Study Design}

Our study was a case-control study that was conducted through the period from August 2018 to July 2019 at the Internal Medicine Department of Aswan University Hospital. The patients were divided into two groups: 1) HCC patients with (chronic HBV or HCV infection) $(\mathrm{n}=30)$; and 2) nonHCC patients with HBV or HCV infection who had either chronic hepatitis or liver cirrhosis $(\mathrm{n}=30)$. In addition, 30 healthy volunteers were included as a control group.

\section{Data Collection}

In the present study, all eligible patients were subjected to:

* Full history taken.

* Physical examination.

* Liver function tests.

* Kidney function tests.

* Detection of serum AFP levels: AFP was detected using the Cobas e411 (Roche) chemiluminescence immunoassay analyzer. It is considered as high if the serum level of AFP is $>7 \mu \mathrm{g} / \mathrm{L}$.

* Detection of serum Golgi protein 73 levels: serum GP73 was determined using an ELISA kit provided by GSCIENCE, Glory Science Co., LTD, USA. Kits adopted on a coated microtiter plate with monoclonal antibody specific for human GP73 make the solid phase antibody. Five standard sample wells and one blank control well were assigned to the microtiter plate. The serum sample of the patient was diluted four times with the diluent of the sample (multiplied by the dilution factor). Then, slanders were added to the assigned wells followed by samples. The microplates were sealed with sealing tapes and incubated at $37{ }^{\circ} \mathrm{C}$ for $60 \mathrm{~min}$. The plates were thoroughly rinsed five times using the washing solution. Then, conjugate was added to form an antibody-antigen-enzymeantibody complex. The plates were sealed with sealing tapes again and incubated at $37{ }^{\circ} \mathrm{C}$ for $30 \mathrm{~min}$. The plates were thoroughly rinsed five times again and each well was supplemented with color reagents A and B TMB substrate solution $\left(50 \mu \mathrm{L}\right.$ each) for the color reaction at $37{ }^{\circ} \mathrm{C}$ for 20 min (TMB substrate becomes blue when HRP enzymecatalyzed). The reaction is finished by the addition of a stop solution and the color change is estimated at a wavelength of $450 \mathrm{~nm}$. Using graph paper, the standard curve is plotted and the concentration of GP73 in the samples is then estimated by comparing the optical density (OD) of the samples to the standard curve.

* HCC group: the diagnosis of HCC was done according to the American Association for the Study of Liver Disease (AASLD) practice guidelines: 1) a single lesion of $1 \mathrm{~cm}$ or more, early arterial enhancement and washout during the delayed venous phase on both dynamic computerized tomography scan (CT) and magnetic resonance imaging (MRI) were required to diagnose $\mathrm{HCC}$; and 2) a lesion of $2 \mathrm{~cm}$ or more, arterial enhancement and washout during the delayed venous phase on at least one imaging 
study were required to diagnose HCC (either dynamic CT scan or MRI).

* Non-HCC group: adult patients with proven cirrhosis or chronic hepatitis. The diagnosis of cirrhosis was done according to clinical, laboratory and imaging data. The symptoms and signs may include ascites, jaundice, bleeding tendency, anorexia, portal hypertension, hypersplenism and encephalopathy. Viral etiology was diagnosed by HBVs antigen and HCV Abs.

\section{Ethical Statement}

We confirm that the present study runs in compatibility with international ethical standards and applicable local regulatory guidelines. The study does not have any physical, psychological, social, legal, economic or any other anticipated risks to the study's participants. Participants in the study were informed about objectives, methods, risks and benefits. A written informed consent was obtained from each eligible patient in the study. The study was reviewed and approved by the ethics committee of the Faculty of Medicine, Aswan University.

\section{Statistical Analysis}

An Excel spreadsheet was performed for data entry. Validation checks are used on numerical variables and an option-based data entry method for categorical variables to minimize potential errors. The analyses were done by SPSS software (Statistical Package for Social Sciences, version 24; IBM Corporation, Armonk, NY, USA). The normality of data was assessed using the Shapiro-Wilk test. Numerical data were described as mean $\pm \mathrm{SD}$ if normally distributed, or median and interquartile range (IQR) if not normally distributed. Frequency tables with percentages were used for categorical variables. Independent Student's $t$-test and ANOVA test were used to compare parametric quantitative variables, while the Mann-Whitney test and Kruskal-Wallis test were used to compare non-parametric quantitative variables. The chi-square test was used to analyze categorical variables. Medcalc program version 15.8 was used to calculate sensitivity, specificity, positive and negative predictive values and ROC curves. A $p$-value $<0.05$ is considered statistically significant.

\section{Results}

Our study included 90 subjects who were divided in equal ratio into the following groups:
1. HCC group: $30 \mathrm{HCC}$ patients with either chronic HBV or HCV infection. The mean age of patients was $63.7 \pm 8.1$ years and the majority of patients were males $(83.3 \%)$.

2. Non-HCC group: 30 patients with HBV or HCV infection who had either chronic hepatitis or liver cirrhosis. The mean age of patients was $59.9 \pm 9$ years and the majority of patients were males $(80 \%)$.

3. Control group: 30 healthy volunteers. The mean age of the group was $38.7 \pm 7.4$ years and the majority were males $(60 \%)$.

There was a statistically significant difference between groups in terms of age $(p<0.001)$. Patients with HCC and non-HCC patients were significantly older than the control group. On the contrary, there was no statistically significant difference between groups in terms of gender $(p=0.81)$ (Table 1).

There was a statistically significant difference between groups in terms of serum albumin $(p<0.001)$, total bilirubin $(p<0.001)$, serum aspartate aminotransferase (AST) $(p<0.001)$, serum alanine aminotransferase (ALT) $(p<0.001)$ and prothrombin time (PT) $(p<0.001)$. NonHCC patients and HCC patients had significantly lower serum albumin and higher total bilirubin, serum AST, serum ALT and PT than the control group (Table 2).

There were statistically significant differences between groups in terms of serum AFP $(p<0.001)$ and GP73

Table I Basic Data of the Study Population

\begin{tabular}{|c|c|c|c|c|}
\hline Variables & $\begin{array}{l}\mathrm{HCC} \\
(\mathrm{N}=30)^{\mathrm{pl}}\end{array}$ & $\begin{array}{l}\text { Non-HCC } \\
\text { (Chronic } \\
\text { Hepatitis } \\
\text { and } \\
\text { Cirrhosis) } \\
(\mathrm{N}=30)^{\mathrm{p} 2}\end{array}$ & $\begin{array}{l}\text { Control } \\
(\mathrm{N}=30)^{\mathrm{p}^{3}}\end{array}$ & $p$-value \\
\hline $\begin{array}{l}\text { Age in years } \\
\text { Mean } \pm S D \\
\text { Median (IQR) }\end{array}$ & $\begin{array}{l}63.7 \pm 8.1^{\mathrm{b}} \\
65(47-80)\end{array}$ & $\begin{array}{l}59.9 \pm 9^{c} \\
58(45-75)\end{array}$ & $\begin{array}{l}38.7 \pm 7.4 \\
39(22-56)\end{array}$ & $<0.001$ \\
\hline $\begin{array}{l}\text { Gender, N (\%) } \\
\text { Male } \\
\text { Female }\end{array}$ & $\begin{array}{l}25(83.3 \%) \\
5(16.7 \%)\end{array}$ & $\begin{array}{l}24(80 \%) \\
6(20 \%)\end{array}$ & $\begin{array}{l}18(60 \%) \\
12(40 \%)\end{array}$ & 0.081 \\
\hline $\begin{array}{l}\text { Viral infection, } \\
\text { N (\%) } \\
\text { HCV } \\
\text { HBV }\end{array}$ & $\begin{array}{l}22(73.3 \%) \\
8(26.7 \%)\end{array}$ & $\begin{array}{l}19(63.3 \%) \\
\text { II (36.7\%) }\end{array}$ & - & 0.091 \\
\hline
\end{tabular}

Notes: Data are presented as mean \pm SD (standard deviation), median (range) or number (\%). ${ }^{b} \mathrm{pl}$ versus $\mathrm{p} 3<0.05 ;{ }^{c} \mathrm{p} 2$ versus $\mathrm{p} 3<0.05$.

Abbreviations: $\mathrm{HCV}$, chronic hepatitis C; $\mathrm{HBV}$, chronic hepatitis $\mathrm{B}$. 
Table 2 Laboratory Characteristics of the Study Population

\begin{tabular}{|c|c|c|c|c|}
\hline Variables & $\begin{array}{l}\text { HCC } \\
(\mathrm{N}=30)^{\mathrm{pI}}\end{array}$ & $\begin{array}{l}\text { Non-HCC Patients (Chronic Hepatitis } \\
\text { and Cirrhosis) }(\mathrm{N}=30)^{\mathrm{p} 2}\end{array}$ & $\begin{array}{l}\text { Control } \\
(\mathrm{N}=30)^{\mathrm{p} 3}\end{array}$ & $p$-value \\
\hline $\begin{array}{l}\text { Albumin (g/dL) } \\
\text { Mean } \pm S D \\
\text { Median (range) }\end{array}$ & $\begin{array}{l}2.8 \pm 0.7^{\mathrm{b}} \\
2.6(2.2-3.3)\end{array}$ & $\begin{array}{l}2.6 \pm 0.5^{c} \\
2.5\left(2.3^{-3.6)}\right.\end{array}$ & $\begin{array}{l}4.3 \pm 0.5 \\
4.2(3.9-4.75)\end{array}$ & $<0.001$ \\
\hline $\begin{array}{l}\text { Bilirubin (mg/dL } \\
\text { Mean } \pm S D \\
\text { Median (range) }\end{array}$ & $\begin{array}{l}3.14 \pm 2.9^{\mathrm{b}} \\
2.9(0.7-3.5)\end{array}$ & $\begin{array}{l}3.5 \pm 3.7^{c} \\
2.2(2.1-5.3)\end{array}$ & $\begin{array}{l}0.58 \pm 0.16 \\
0.5(0.45-0.75)\end{array}$ & $<0.001$ \\
\hline $\begin{array}{l}\text { AST (IU/L) } \\
\text { Mean } \pm \text { SD } \\
\text { Median (range) }\end{array}$ & $\begin{array}{l}54.2 \pm 15.8^{b} \\
50.5(36-95)\end{array}$ & $\begin{array}{l}48.1 \pm 8^{c} \\
48(33-62)\end{array}$ & $\begin{array}{l}23.8 \pm 6 \\
23(17-34)\end{array}$ & $<0.001$ \\
\hline $\begin{array}{l}\text { ALT (IU/L) } \\
\text { Mean } \pm \text { SD } \\
\text { Median (range) }\end{array}$ & $\begin{array}{l}68.3 \pm 20.2^{\mathrm{b}} \\
67(42-11 \mathrm{l})\end{array}$ & $\begin{array}{l}65.5 \pm 20^{c} \\
60(42-102)\end{array}$ & $\begin{array}{l}25.4 \pm 5.4 \\
24(18-32)\end{array}$ & $<0.001$ \\
\hline $\begin{array}{l}\text { PT (seconds) } \\
\text { Mean } \pm S D \\
\text { Median (range) }\end{array}$ & $\begin{array}{l}16.8 \pm 6.7^{\mathrm{b}} \\
15.8(|4.9-| 7.1)\end{array}$ & $\begin{array}{l}16.6 \pm 1.8^{c} \\
16.4(15.5-18)\end{array}$ & $\begin{array}{l}12 \pm 0.8 \\
12(11.3-12.8)\end{array}$ & $<0.001$ \\
\hline
\end{tabular}

Notes: Data are presented as mean \pm SD (standard deviation) or median (range). ${ }^{b} \mathrm{pl}$ versus $\mathrm{p} 3<0.05 ;{ }^{c} \mathrm{p} 2$ versus $\mathrm{p} 3<0.05$.

Abbreviations: AST, aspartate aminotransferase; ALT, alanine aminotransferase; PT, prothrombin time.

$(p<0.001)$. Non-HCC patients and HCC patients had significantly higher AFP and GP73 than the control group. In addition, patients with HCC had significantly higher AFP and GP73 than non-HCC patients (Table 3).

AFP was a significant discriminator of HCC. At a cutoff value of $\geq 2.4 \mathrm{ng} / \mathrm{mL}$, AFP yielded a sensitivity of $75.4 \%$ and specificity of $90 \%$ for the discrimination between HCC and normal populations. Similarly, at a cutoff value of $\geq 20.85 \mathrm{ng} / \mathrm{mL}$, AFP yielded a sensitivity of $72.2 \%$ and specificity of $86.2 \%$ for the discrimination between HCC and non-HCC patients (Table 4) (Figure 1).

GP73 was a significant discriminator of HCC. At a cut-off value of $\geq 8.4 \mathrm{ng} / \mathrm{mL}, \quad$ GP73 yielded a sensitivity of $86.7 \%$ and specificity of $89 \%$ for the

Table 3 Biomarker Findings of the Study Population

\begin{tabular}{|c|c|c|c|c|}
\hline Variables & $\mathrm{HCC}(\mathrm{N}=30)^{\mathrm{pl}}$ & $\begin{array}{l}\text { Non-HCC Patients (Chronic } \\
\text { Hepatitis and Cirrhosis) }(\mathrm{N}=30)^{\mathrm{p} 2}\end{array}$ & Control $(\mathrm{N}=30)^{\mathrm{p} 3}$ & p-value \\
\hline $\begin{array}{l}\text { AFP } \\
\qquad \begin{array}{l}\text { Mean } \pm S D \\
\text { Median (IQR) }\end{array}\end{array}$ & $\begin{array}{l}1085.2 \pm 1465.4^{\mathrm{a}, \mathrm{b}} \\
536.5(8-4840)\end{array}$ & $\begin{array}{l}22 \pm 19.6^{\mathrm{a}, \mathrm{c}} \\
21(2.6-87)\end{array}$ & $\begin{array}{l}1.24 \pm 0.38 \\
\text { I.I }(0.9-1.9)\end{array}$ & $<0.001$ \\
\hline $\begin{array}{l}\text { GP73 } \\
\quad \text { Mean } \pm S D \\
\text { Median (IQR) }\end{array}$ & $\begin{array}{l}I I . I \pm 8.5^{\mathrm{a}, \mathrm{b}} \\
8.9(0.88-33)\end{array}$ & $\begin{array}{l}4.4 \pm 2.9^{\mathrm{a}, \mathrm{c}} \\
3.3(1.9-12.9)\end{array}$ & $\begin{array}{l}1.4 \pm 1.6 \\
0.6(0.19-5.6)\end{array}$ & $<0.001$ \\
\hline
\end{tabular}

Notes: Data are presented as mean \pm SD (standard deviation) or median (range). ${ }^{a} \mathrm{pl}$ versus $\mathrm{p} 2<0.05$; ${ }^{\mathrm{b}} \mathrm{pl}$ versus $\mathrm{p} 3<0.05$; ${ }^{\mathrm{c}} \mathrm{p} 2$ versus $\mathrm{p} 3<0.05$. Abbreviations:- AFP, alpha-fetoprotein; GP73, Golgi protein 73.

Table 4 The Area Under the Curve and Diagnostic Accuracy of AFP

\begin{tabular}{|c|c|c|c|c|c|c|c|}
\hline Variable & AUC, $95 \% \mathrm{Cl}$ & $P$-value & Cut-Off Points & Sensitivity & Specificity & PPV & NPV \\
\hline $\mathrm{HCC}$ versus control & $0.85(0.61-100.0)$ & 0.001 & $\geq 2.4 \mathrm{ng} / \mathrm{mL}$ & $75.4 \%$ & $90 \%$ & $88.3 \%$ & $78.5 \%$ \\
\hline $\mathrm{HCC}$ versus non-HCC patients & $0.85(0.80-0.90)$ & 0.001 & $\geq 20.85 \mathrm{ng} / \mathrm{mL}$ & $72.2 \%$ & $86.2 \%$ & $83.9 \%$ & $75.9 \%$ \\
\hline
\end{tabular}

Abbreviations: $\mathrm{HCC}$, hepatocellular carcinoma; AUC, area under the curve; $\mathrm{Cl}$, confidence interval; PPV, positive predictive value; NPV, negative predictive value. 


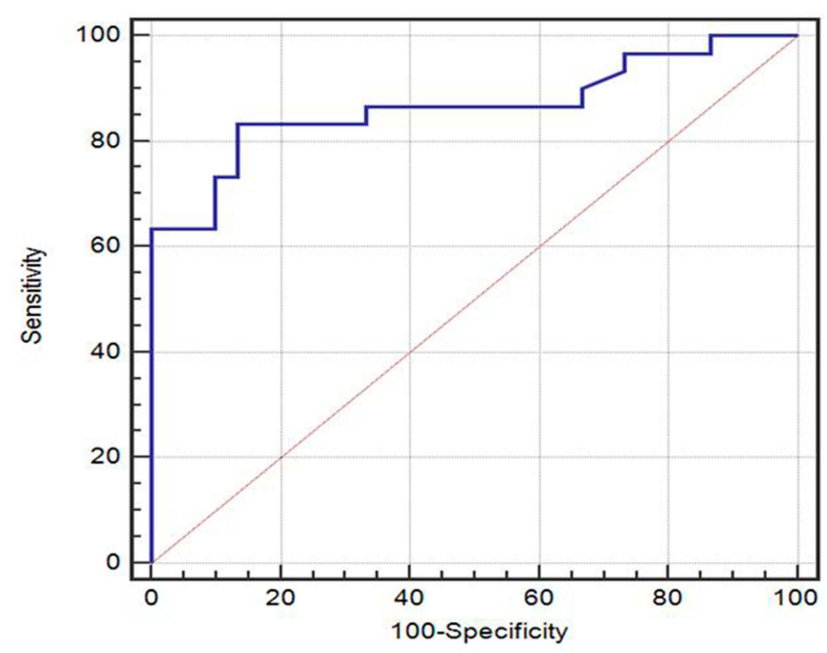

Figure I The area under the curve and diagnostic accuracy of AFP for HCC patients versus non-HCC patients (chronic hepatitis and liver cirrhosis). Abbreviations: AFP, alpha-fetoprotein; HCC, hepatocellular carcinoma.

discrimination between $\mathrm{HCC}$ and normal populations. Similarly, at a cut-off value of $\geq 8.45 \mathrm{ng} / \mathrm{mL}$, GP73 yielded a sensitivity of $83.3 \%$ and specificity of $84 \%$ for the discrimination between $\mathrm{HCC}$ and non-HCC patients (Table 5) (Figure 2).

There was a significant association between both biomarkers. Patients with $A F P \geq 20 \mathrm{ng} / \mathrm{mL}$ had significantly higher GP73 values than patients with $\mathrm{AFP}<20 \mathrm{ng} / \mathrm{mL}(p<0.001)$. The combination of both biomarkers yielded a sensitivity of $97 \%$ and specificity of $89 \%$ for the differentiation between HCC and normal populations. Similarly, the combination yielded a sensitivity of $91 \%$ and specificity of $86 \%$ for the differentiation between $\mathrm{HCC}$ and non-HCC patients (Figure 3).

\section{Discussion}

Our study included 90 subjects who were divided in equal ratio into the following groups:

1. HCC group: $30 \mathrm{HCC}$ patients with either chronic HBV or HCV infection. The mean age of patients was $63.7 \pm 8.1$ years and the majority of patients were males $(83.3 \%)$.

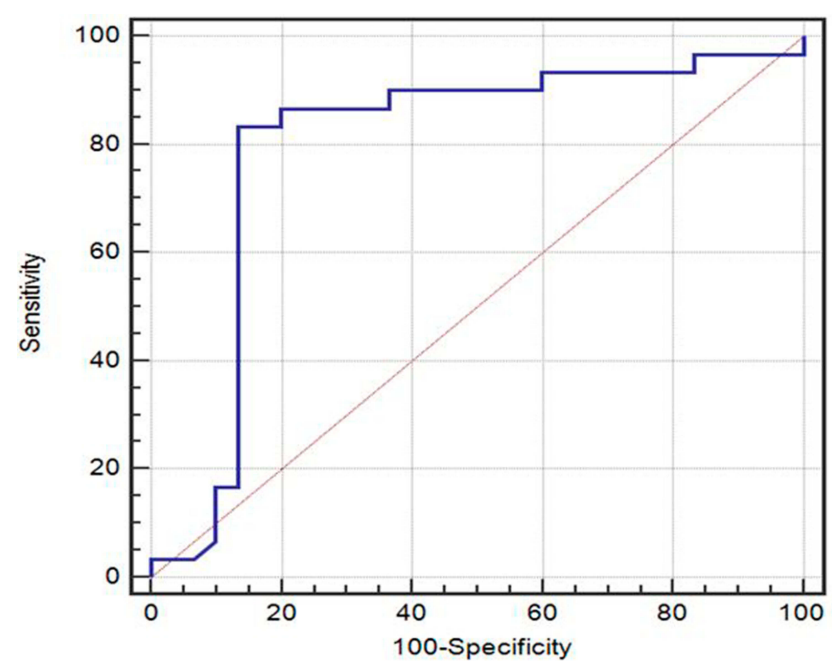

Figure 2 The area under the curve and diagnostic accuracy of GP73 for HCC patients versus non-HCC patients (chronic hepatitis and liver cirrhosis). Abbreviations: GP73, Golgi protein 73; HCC, hepatocellular carcinoma.

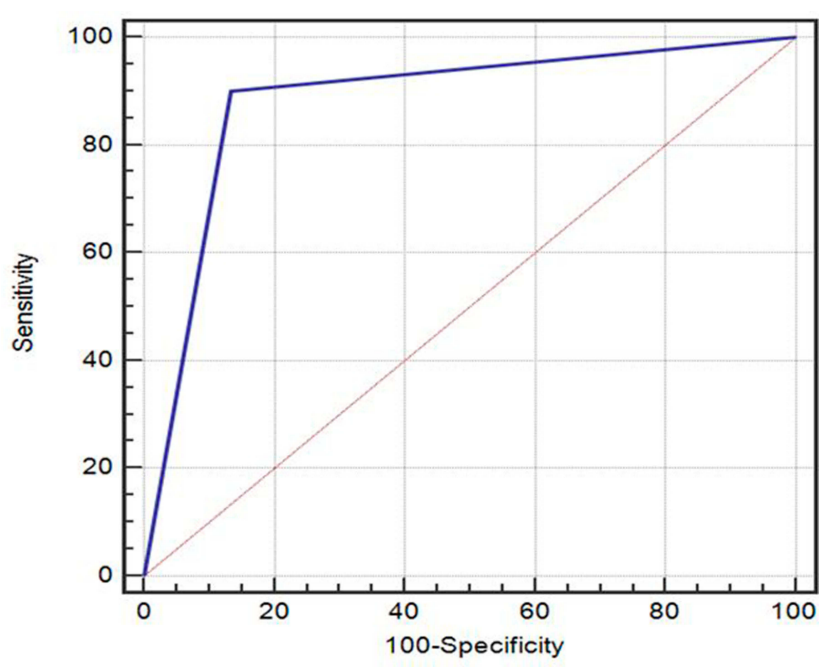

Figure 3 The area under the curve and diagnostic accuracy of the combination of GP73 and AFP for HCC patients versus non-HCC patients (chronic hepatitis and liver cirrhosis).

Abbreviations: AFP, alpha-fetoprotein; GP73, Golgi protein 73; HCC, hepatocellular carcinoma.

2. Non-HCC group: 30 patients with $\mathrm{HBV}$ or $\mathrm{HCV}$ infection who had either chronic hepatitis or liver cirrhosis. The mean age of patients was $59.9 \pm 9$ years and the majority of patients were males $(80 \%)$.

Table 5 The Area Under the Curve and Diagnostic Accuracy of GP73

\begin{tabular}{|c|c|c|c|c|c|c|c|}
\hline Variable & AUC, $95 \% \mathrm{Cl}$ & p-value & Cut-Off Points & Sensitivity & Specificity & PPV & NPV \\
\hline $\mathrm{HCC}$ versus control & $0.96(0.92-0.99)$ & 0.001 & $\geq 8.4 \mathrm{ng} / \mathrm{mL}$ & $86.7 \%$ & $89 \%$ & $88.7 \%$ & $86.9 \%$ \\
\hline $\mathrm{HCC}$ versus non-HCC patients & $0.83(0.72-0.93)$ & 0.001 & $\geq 8.45 \mathrm{ng} / \mathrm{mL}$ & $83.3 \%$ & $84 \%$ & $86.2 \%$ & $81.5 \%$ \\
\hline
\end{tabular}

Abbreviations: HCC, hepatocellular carcinoma; AUC, area under the curve; Cl, confidence interval; PPV, positive predictive value; NPV, negative predictive value. 
3. Control group: 30 healthy volunteers. The mean age of the group was $38.7 \pm 7.4$ years and the majority were males $(60 \%)$.

HCC is characterized by more male incidence than females. The male-to-female incidence ratio of HCC varies between $2: 1$ and $4: 1$. Older age above 50 years is a certain risk factor for $\mathrm{HCC}^{5}$ On the other hand, chronic viral hepatitis can lead to cirrhosis and/or HCC. Chronic hepatitis $\mathrm{B}$ and $\mathrm{C}$ are the most common causes of chronic hepatitis in the world. ${ }^{6}$

In line with our findings, Alswat et $\mathrm{al}^{7}$ conducted a retrospective study to evaluate the clinical features and outcomes of HCC in Saudi Arabia in two tertiary care centers. Patients who have been diagnosed with hepatocellular carcinoma are included in the study. The study was about 5 years from June 2003 to July 2008, and 363 patients were included in the study. The mean age of patients was 66 years, $74 \%$ of patients were males and hepatitis $\mathrm{C}$ was the main dominant cause of liver disease in $48 \%$ of patients.

AFP was first described in 1953 as a fetal form of albumin and a marker for HCC. It has since become the best described and most used marker in HCC. It has been recognized for its usefulness in prognosis, its relationship to various indices of HCC human biology, its use in nonbiopsy HCC diagnosis, its use in evaluation of responses to treatment and also can be used for screening of HCC which is done usually with imaging tools especially abdominal ultrasound in patients with hepatitis or cirrhosis who are known to be at risk for HCC development. However, not all HCC tumors are AFP positive or secrete elevated amounts of AFP into the serum. ${ }^{8}$

In our study, we found that non-HCC patients and HCC patients had significantly higher AFP than the control group. In addition, patients with $\mathrm{HCC}$ had significantly higher AFP than non-HCC patients. However, the diagnostic accuracy of AFP was relatively low. At a cut-off value of $\geq 2.4 \mathrm{ng} / \mathrm{mL}$, AFP yielded a sensitivity of $75.4 \%$ and specificity of $90 \%$ for the discrimination between HCC and normal populations. Similarly, at a cut-off value of $\geq 20.85 \mathrm{ng} / \mathrm{mL}$, AFP yielded a sensitivity of $72.2 \%$ and specificity of $86.2 \%$ for the discrimination between HCC and non-HCC patients.

In agreement with our findings, Soresi et $\mathrm{al}^{9}$ evaluated the best cut-off value for serum AFP to differentiate between liver cirrhosis and HCC. The study included 372 patients with liver cirrhosis and 197 with HCC-associated cirrhosis. The area under the ROC curve was $0.81 \pm 0.02$; the best determined cut-off value was $20 \mathrm{ng} / \mathrm{mL}$. At this level, sensitivity was $65 \%$ and specificity $89 \%$.

More recently, Mehinovic et $\mathrm{al}^{10}$ aimed to evaluate the diagnostic value of AFP in estimation of patients with HCC from cirrhotic patients and also to analyze the potential correlation between AFP levels and stages of liver cirrhosis. Their study included 50 patients with HCC and 50 patients with liver cirrhosis. Most of the study populations were males and chronic hepatitis $\mathrm{B}$ was the main etiology. HCC patients had high AFP values in comparison to patients with liver cirrhosis. An AFP value of 23.34 $\mathrm{ng} / \mathrm{mL}$ showed a sensitivity of $84 \%$ and specificity of $82 \%$.

On the contrary, other studies reported a much lower diagnostic performance of AFP for discrimination of HCC. Ahn et $\mathrm{al}^{11}$ examined retrospective medical records of cirrhotic patients and HCC patients in three hospitals in Korea, aiming to determine the likelihood of using AFP as a diagnostic tool for HCC. The study included 732 patients with liver cirrhosis or $\mathrm{HCC}$ and control persons. The area under the curve for all HCC patients was 0.757. The sensitivity, specificity and positive predictive value of AFP at a cut-off of $20 \mathrm{ng} / \mathrm{mL}$ was $50.55 \%, 87.70 \%$ and $80.43 \%$, respectively.

Similarly, Durazo et al ${ }^{12}$ performed a prospective study to determine the optimum level of AFP with the best sensitivity and specificity for HCC diagnosis. The study included 240 patients divided into 144 with HCC, 47 with chronic hepatitis and 49 with cirrhosis. The results of their study showed that the cut-off value with the best sensitivity and specificity for AFP was $\geq 25 \mathrm{ng} / \mathrm{mL}$. Sensitivity, specificity and positive predictive value for AFP were $69 \%, 87 \%$ and $69.8 \%$, respectively.

Our explanation for lower sensitivity in previous studies is that our study only involves patients with viral etiology, whereas in previous studies viral etiology was dominant, but other etiologies were also involved.

A good prognostic biomarker should have no significant correlation with demographic characteristics. Our study showed that there were no statistically significant correlations between serum GP73 and demographic data (including age and gender).

In agreement with our findings, Jiao et $\mathrm{al}^{13}$ did their study on 443 patients (180 patients with HCC, 61 patients with liver cirrhosis, 99 patients with chronic hepatitis, 103 healthy control subjects) aiming to determine the diagnostic value of GP73 for HCC diagnosis and also the correlation between the GP73 level and demographic data of HCC patients. The results showed no correlation between 
gender or age and serum GP73 level within the HCC group.

Similarly, Wang et $\mathrm{al}^{14}$ did their study on 60 liver transplantation patients and 72 healthy subjects aiming to determine the correlation between the GP73 level and tumor recurrence after liver transplantation. They estimated serum GP73 and AFP levels. Their results showed no correlation between gender or age and serum GP73 level within the HCC group.

Regarding the primary outcome of the present study, we found that there were statistically significant differences between groups in terms of GP73 $(p<0.001)$. NonHCC patients and HCC patients had significantly higher GP73 than the control group. In addition, patients with HCC had significantly higher GP73 than non-HCC patients. Notably, GP73 had higher diagnostic performance than AFP. At a cut-off value of $\geq 8.4 \mathrm{ng} / \mathrm{mL}$, GP73 yielded a sensitivity of $86.7 \%$ and specificity of $89 \%$ for the discrimination between HCC and normal populations. Similarly, at a cut-off value of $\geq 8.45 \mathrm{ng} / \mathrm{mL}$, GP73 yielded a sensitivity of $83.3 \%$ and specificity of $84 \%$ for the discrimination between $\mathrm{HCC}$ and non-HCC patients.

In concordance with our findings, Yang et al ${ }^{15}$ did 11 studies (meta-analysis studies) aiming to estimate the diagnostic accuracy of GP73 as sensitivity and specificity. The summary of their results for GP73 serum levels as a biomarker in the diagnosis of HCC was as follows: sensitivity, 77\% (95\% CI, 75-79\%); and specificity, 91\% (95\% CI, 90-92\%).

Moreover, Zhou et al $^{16}$ performed eight meta-analysis studies to evaluate the diagnostic accuracy as sensitivity, specificity and other measures for serum GP73 in comparison to AFP for diagnosis of HCC. Their results summary in the included studies for serum GP73 and AFP in HCC diagnosis was as follows: sensitivity, 76\% (95\% CI, $51-91 \%)$ vs $70 \%$ (47-86\%); and specificity, 86\% (95\% CI, 65-95\%) vs 89\% (69-96\%).

The exact mechanism by which the GP73 increases in $\mathrm{HCC}$ is not known, but the exact mechanism by which GP73 can pass into circulation has been worked out in multiple cell culture studies. GP73 has been shown to be overexpressed and detected in malignant liver tumors compared to non-cancer tissues. It is noted also that the degree of GP73 expression was correlated with the tumor number and size. ${ }^{17}$

However, it should be noted that other published studies reported lower sensitivity of GP73. In Marrero et al's ${ }^{18}$ study, GP73 had a sensitivity of $69 \%$ and specificity of $75 \%$ at the optimal cut-off point. GP73 levels were significantly more sensitive than AFP for early diagnosis of HCC $(P<0.0001)$.

Also, Shi et al ${ }^{19}$ performed their study on 73 patients with HCC, 13 patients with cirrhosis, 32 patients with chronic hepatitis and 62 healthy persons to determine the diagnostic accuracy of GP73 and AFP in diagnosing HCC. The sensitivity for serum GP73 and AFP in the diagnosis of HCC was $68.5 \%$ and $28.8 \%$, respectively.

Again, the exact causes of lower sensitivity in the abovementioned studies than in our study are unclear. However, this can be attributed to different population characteristics as we included only patients with viral etiology.

Notably, our analysis demonstrated that the combination of GP73 and AFP yielded a sensitivity of 97\% and specificity of $89 \%$ for the discrimination between $\mathrm{HCC}$ and normal populations. Similarly, the combination yielded a sensitivity of $91 \%$ and specificity of $86 \%$ for the discrimination between HCC and non-HCC patients.

Similarly, in Dai et al's ${ }^{20}$ multiple meta-analytic studies for evaluation of diagnostic accuracy of combined GP73 and APF levels, the summary of their results showed the following: pooled sensitivity and specificity were, respectively, 0.77 (95\% CI: 0.75-0.79) and 0.91 (95\% CI: 0.90-0.92) for GP73; 0.62 (95\% CI: 0.60-0.64) and 0.84 (95\% CI: 0.83-0.85) for AFP; and 0.87 (95\% CI: $0.85-$ $0.89)$ and 0.85 (95\% CI: $0.84-0.86)$ for GP73 plus AFP.

\section{Conclusion}

Golgi protein 73 is a promising and good biomarker for early detection of $\mathrm{HCC}$ that can be a novel risk stratification factor and a potential therapeutic molecular target for HCC. Our study showed that the level of GP73 was significantly higher in $\mathrm{HCC}$ patients in comparison to non-HCC patients (chronic hepatitis and liver cirrhosis) and a healthy population. This study demonstrated a moderate value of GP73 in HCC diagnosis. GP73 exhibited also a higher diagnostic accuracy than AFP; while a combination of GP73 plus AFP for HCC detection had a higher diagnostic performance than each biomarker alone. However, some limitations, such as being a small sample-sized, single-centre study and including only viral etiology, have been considered in our study. So, further and more studies with strict designs, large sample sizes, different etiologies and multiple collaboration centers are therefore needed. 


\section{Disclosure}

The authors declare that they have no competing interests.

\section{References}

1. Kulik L, El-Serag HB. Epidemiology and management of hepatocellular carcinoma. Gastroenterology. 2019;156(2):477-491. e471. doi:10.1053/j.gastro.2018.08.065

2. Dimitroulis D, Damaskos C, Valsami S, et al. From diagnosis to treatment of hepatocellular carcinoma: an epidemic problem for both developed and developing world. World J Gastroenterol. 2017;23 (29):5282. doi:10.3748/wjg.v23.i29.5282

3. Ocker M. Biomarkers for hepatocellular carcinoma: what's new on the horizon? World J Gastroenterol. 2018;24(35):3974. doi:10.3748/wjg. v24.i35.3974

4. Farag RMA, Al Ayobi D, et al. Studying the impact of Golgi protein 73 serving as a candidate biomarker in early diagnosis for hepatocellular carcinoma among Saudi patients. Asian Pac J Cancer Prev. 2019;20(1):215. doi:10.31557/APJCP.2019.20.1.215

5. Liu P, Xie S-H, Hu S, et al. Age-specific sex difference in the incidence of hepatocellular carcinoma in the United States. Oncotarget. 2017;8(40):68131.

6. Westwood M, Joore M, Grutters J, et al. Contrast-enhanced ultrasound using SonoVue ${ }^{\circledR}$ (sulphur hexafluoride microbubbles) compared with contrast-enhanced computed tomography and contrast-enhanced magnetic resonance imaging for the characterisation of focal liver lesions and detection of liver metastases: a systematic review and cost-effectiveness analysis. Health Technol Assess. 2013;17(16): 1.

7. Alswat KA, Sanai FM, Altuwaijri M, et al. Clinical characteristics of patients with hepatocellular carcinoma in a middle eastern population. Hepat Mon. 2013;13:5. doi:10.5812/hepatmon.7612

8. Carr BI, Akkiz H, Üsküdar O, et al. HCC with low-and normal-serum alpha-fetoprotein levels. Clin Pract. 2018;15(1):453.

9. Soresi M, Magliarisi C, Campagna $P$, et al. Usefulness of alpha-fetoprotein in the diagnosis of hepatocellular carcinoma. Anticancer Res. 2003;23(2C):1747-1753.
10. Mehinovic L, Islamagic E, Husic-Selimovic A, Kurtovic-Kozaric A, Vukobrat-Bijedic Z, Suljevic D. Evaluation of diagnostic efficiency of alpha-fetoprotein in patients with liver cirrhosis and hepatocellular carcinoma: single-center experience. Open Access Maced J Med Sci. 2018;6(9):1668. doi:10.3889/oamjms.2018.344

11. Ahn DG, Kim HJ, Kang H, et al. Feasibility of $\alpha$-fetoprotein as a diagnostic tool for hepatocellular carcinoma in Korea. Korean J Intern Med. 2016;31(1):46. doi:10.3904/kjim.2016.31.1.46

12. Durazo FA, Blatt LM, Corey WG, et al. Des- $\gamma$-carboxyprothrombin, $\alpha$-fetoprotein and AFP-L3 in patients with chronic hepatitis, cirrhosis and hepatocellular carcinoma. J Gastroenterol Hepatol. 2008;23 (10):1541-1548. doi:10.1111/j.1440-1746.2008.05395.x

13. Jiao C, Cui L, Piao J, Qi Y, Yu Z. Clinical significance and expression of serum Golgi protein 73 in primary hepatocellular carcinoma. J Cancer Res Ther. 2018;14(6):1239.

14. Wang Y, Zhang Z, Zou D, et al. Serum Golgi protein 73 is a prognostic biomarker of liver transplantation patients. Int $J$ Clin Exp Pathol. 2017;10(8):8626-8632.

15. Yang J, Li J, Dai W, et al. Golgi protein 73 as a biomarker for hepatocellular carcinoma: a diagnostic meta-analysis. Exp Ther Med. 2015;9(4):1413-1420. doi:10.3892/etm.2015.2231

16. Zhou Y, Yin X, Ying J, Zhang B. Golgi protein 73 versus alpha-fetoprotein as a biomarker for hepatocellular carcinoma: a diagnostic meta-analysis. BMC Cancer. 2012;12(1):17. doi:10.11 86/1471-2407-12-17

17. AlSalloom AAM. An update of biochemical markers of hepatocellular carcinoma. Int J Health Sci. 2016;10(1):121. doi:10.12816/0031219

18. Marrero JA, Romano PR, Nikolaeva O, et al. GP73, a resident Golgi glycoprotein, is a novel serum marker for hepatocellular carcinoma. J Hepatol. 2005;43(6):1007-1012. doi:10.1016/j.jhep.2005.05.028

19. Shi Y, Chen J, Li L, et al. A study of diagnostic value of golgi protein GP73 and its genetic assay in primary hepatic carcinoma. Technol Cancer Res Treat. 2011;10(3):287-294. doi:10.7785/tcrt.2012.500205

20. Dai M, Chen X, Liu X, Peng Z, Meng J, Dai S. Diagnostic value of the combination of Golgi protein 73 and alpha-fetoprotein in hepatocellular carcinoma: a meta-analysis. PLoS One. 2015;10(10): e0140067. doi:10.1371/journal.pone.0140067
International Journal of General Medicine

\section{Publish your work in this journal}

The International Journal of General Medicine is an international, peer-reviewed open-access journal that focuses on general and internal medicine, pathogenesis, epidemiology, diagnosis, monitoring and treatment protocols. The journal is characterized by the rapid reporting of reviews, original research and clinical studies across all disease areas. The manuscript management system is completely online and includes a very quick and fair peer-review system, which is all easy to use. Visit http://www.dovepress.com/ testimonials.php to read real quotes from published authors. 